\title{
Universidad desplazada (desalojada)
}

\section{Disestablished university}

Gerardo Roacho Payán ${ }^{1}$

Laura Verónica Herrera Ramos ${ }^{2}$

\begin{abstract}
Resumen
La universidad como institución social ha sido históricamente conceptualizada de forma diversa en relación a los imaginarios de la sociedad que la crea, tanto desde sus orígenes, hasta la actualidad; sea en el medievo, con injerencia de lo religioso en el saber; sea bajo los ideales de la ilustración, con sus principios centrados en la razón para relegar la ignorancia y la superstición; y por último, por la visión positivista y conductual, cuya visión de racionalidad e instrumental fría, buscaba el dominio del hombre y la naturaleza. Lo común de esta revisión histórica, es que la universidad ha sido creada como una institución conformada por un grupo social y está dedicada al saber, y que por sus implicaciones, reviste de una organización para su adecuado funcionamiento. En la Universidad Pedagógica Nacional del Estado de Chihuahua (UPNECH), creada por decreto por el gobierno del estado el 6 de agosto de 2011 como Organismo Público Descentralizado del Gobierno Estatal, adscrito a la Secretaría de Educación, Cultura y Deporte del Poder Ejecutivo del Estado, empero, ambas condiciones se encuentran en crisis en tanto complejidad científica, económica, social y política. Este estudio pretende demarcar las crisis de la UPNECH, manifestadas en la segunda condición y, como se manifiesta institucionalmente la tensión (en los imaginarios sociales) resultante desde un nivel estatal a lo grupal e individual apoyado bajo la mirada de la teoría simbólica y el psicoanálisis.
\end{abstract}

1 Gerardo Roacho Payán. Profesor-investigador en la Universidad Pedagógica Nacional del Estado de Chihuahua, Campus Parral, México. Es maestro en Psicoterapia. Correo electrónico: groacho@gmail.com ID: http://orcid.org/0000-0002-7229-5456

2 Laura Verónica Herrera Ramos. Profesora-investigadora en la Universidad Pedagógica Nacional del Estado de Chihuahua, Campus Parral, México. Es doctora en pedagogía crítica. Correo electrónico: veronica19732014@gmail.com

ID: http://orcid.org/0000-0001-8785-0603 
RECIE. Revista Electrónica Científica de Investigación Educativa Vol. 4, núm. 2, enero-diciembre 2019, pp. 1083-1091.

\title{
Palabras clave \\ Universidad, imaginario, cultura, agresión, sublimación.
}

\begin{abstract}
The university as a social institution has been historically conceptualized in a diverse way in relation to the imaginaries of the society that creates them, from both its origins to current times; being in medieval times, with religious interference in knowledge; being under the ideals of illustration with its principles based in reason in order to delegate ignorance and superstition; and finally being for the positivist and behavioral vision which rationality and a cold instrumental vision was looking for mankind and nature dominance. The ordinary of this historical revision, the university has been created as an institution formed by a social group and it is dedicated to knowledge, and because of its implications, comes from an organization for its adequate functioning. In the National Pedagogical University of Chihuahua State in Mexico (UPNECH) created by a decree by the state government on August $6^{\text {th }}$ 2011as a public and decentralized organism of the state government ascribed to the bureau of education, sports and culture of the executive branch of the state, both conditions are in crisis in respect to scientific, economic, social and political complexity. This study pretends to remark the crisis in the UPNECH expressed in the second condition and, the way the tension is institutionally manifested (in the social imaginaries) resulting from a state level to the group and individual supported under the view of the symbolic theory and psychoanalysis.
\end{abstract}

\section{Keywords}

University, imaginary, culture, aggression, sublimation.

\section{Introducción}

La Licenciatura en Intervención Educativa (LIE) plan 2002, surge como parte de la necesidad de reorientar la oferta educativa de la Universidad Pedagógica Nacional (UPN) para trascender en su actuar, el tránsito de la profesionalización del magisterio en servicio, a una Institución de Educación Superior, la cual tiene "por finalidad prestar, desarrollar y orientar servicios educativos de tipo superior encaminados a la formación de profesionales de la educación" (LIE, 2002; p. 15), sin abandonar la tradición crítica y reflexiva que le caracteriza en la formación de sus estudiantes. El presente estudio, intenta aproximarse a su objeto en relación a cuestionarse, primero, ¿De qué 
manera se establecen persuasiones ideológicas por parte del carácter institucional en algunos estudiantes de la LIE y como repercuten en estallamiento de relaciones interpersonales conflictivas entre estos, en tanto ruptura y antinomia del imaginario de la visión de mundo y de la vida en la que se funda la UPN?; además, ¿Cómo influye el imaginario de la disidencia estatal investido por algunos catedráticos para contrarrestar ese proceso de manipulación y persuasión del imaginario funcionalista de la Universidad? El estudio tiene dos propósitos, en primer lugar, develar y denunciar las relaciones de poder emergidas a través del carácter institucional funcionalista y en segundo si su materialización en un panóptico instituido en algunos alumnos de un grupo de la LIE, impacta en la constitución de relaciones interpersonales conflictivas.

\section{Metodología}

Se parte del método hermenéutico o concepción estructural de la cultura de John B. Thompson, que pertenecen a un enfoque cualitativo, el cual plantea observar las diversas formas simbólicas y su vínculo con los contextos sociales en las que están inscritos. La posición de este método, se apoya en los trabajos de Dilthey, Heidegger, Gadamer, Ricour, Levis Straus, Bordieu, entre otros. Es definido como una visión de comprensión, en tanto según Gimenez (1994), abarca los fenómenos culturales representados en formas simbólicas para ser comprendidas e interpretadas. Formas simbólicas tomadas en cuenta a partir de opiniones, creencias y juicios que establecen y son compartidos por actores sociales en función a relaciones de poder, oportunidades de acceso a recursos sociales, etc. Indaga en los sujetos investigados: profesores y estudiantes del $2^{\circ}$. Semestre de la LIE, procesos de valoración simbólica de la vida cotidiana, en tanto estudio de fenómenos sociales y culturales, utilizando el análisis formal del discurso para ser comprendido e interpretado. La teoría crítica afirma que toda interpretación puede ser sesgada, por lo que para encontrar y comprender los significados del objeto de estudio, es necesario considerar las fuerzas sociales, políticas y económicas, y, la raza, clase social y género. Este método concreta la delimitación del objeto de estudio, utiliza técnicas como la entrevista, charlas informales, cuestionario y análisis de textos para cuestionar el dato empírico con el referente teórico y dar sentido a la hegemonía en la universidad y su repercusión en los actores insertos en ella. 
RECIE. Revista Electrónica Científica de Investigación Educativa Vol. 4, núm. 2, enero-diciembre 2019, pp. 1083-1091.

\section{Resultados preliminares}

La universidad, de la expresión simbólica funcional a la manifestación simbólica alternativa

La UPN en su creación, surge como propuesta en 1970 por el Sindicato Nacional de Trabajadores de la Educación, con el fin de profesionalizar al magisterio; en 1975, el mismo organismo demanda su consolidación al candidato presidencial, y por fin, en 1978, se crea por Decreto Presidencial, publicado el 29 de agosto del año señalado. De noviembre de 1979 a la fecha, se han conformado 75 unidades UPN en el país, quienes operan con diversas licenciaturas. Así mismo, en 2001, se publica por el diario señalado, la ubicación de la institución en la Subsecretaria de Educación Superior e Investigación Científica (SESIC), lo que implica un tránsito del nivel de educación básica al nivel de educación superior, lo que moviliza la adaptación de sus recursos, previo a un Plan de Acción Institucional, para otorgar servicios a otros usuarios, creando la LIE Plan 2002. Desde sus orígenes, la UPN tiene como principios rectores prestar, desarrollar y orientar la educación superior a formar profesionales de la educación a través de criterios que les permita tener una visión humanista, democrática, crítica y científica para la transformación de la realidad y de sí mismos (dialéctica). Visión que aun trasciende en algunos de sus alumnos de posgrado, al reconocer "que la UPN me ha dado una visión de la educación, al identificar aspectos ocultos sobre el manejo del poder, que no había visto en la educación ni en mi práctica" (charla informal; 2018). Sin embargo, el emerger del sindicalismo y de la Secretaria de Educación Pública y posteriormente consolidada en UPNECH, como organismo descentralizado dependiente del gobierno del estado de Chihuahua, permite observar que la universidad, según Santos (2007), se sumerge en tres crisis: crisis de hegemonía, en tanto que ha perdido su carácter intelectual; de legitimidad, por su segmentación y desvalorización de los diplomas que emite y, la que importa para efectos de este estudio, la crisis institucional, manifestada en relación a su pérdida de autonomía científica y pedagógica por su dependencia financiera con el Estado.

La universidad al pertenecer financiera y administrativamente al Estado, impone en ella un estatus de organización económica funcional, constituida por las significaciones imaginarias sociales de sus creadores (SNTE, SESIC, y como UPNECH), desde sus cotas simbólicas funcionalistas emprendedoras del orden y de las reglamentaciones. Se está de acuerdo con Castoriadis (2013), al mencionar que no se cuestiona la visión funcionalista en la medida de que las instituciones cumplen funciones vitales sin las cuales la 
existencia de una sociedad es insostenible, pero si se cuestiona la visión funcionalista, ahí donde debía estar su punto central: cuáles son las necesidades reales de una sociedad, cuyas instituciones están ahí para servir. Por lo tanto y es contrario a lo referido por Murcia y Gamboa (2015), "la universidad como escenario y origen del saber cómo escenario y por tanto origen de autonomía y construcción social, en la que los imaginarios respecto de las sociedades y las ciencias han llevado a forjarla como institución autónoma”. Sin embargo, no se visibiliza su autonomía de lo real, en tanto necesidades de la propia institución y por la dependencia financiera y administrativa, difícilmente sus fundamentos filosóficos y pedagógicos críticos serán expresión viviente y coherente. Sin embargo, en UPNECH, aparentemente se visibiliza su pretensión originaria; como comunidad universitaria con sinergia propia, como constituyente e instituyente de sus propias significaciones imaginarias, en tanto asunción de sus propios fundamentos filosóficos y pedagógicos para crear actores y una sociedad con significaciones imaginarias y sociales críticas que tiende a una franca oposición a simbolismos funcionalistas. "Es consabido que en la UPN existen muchos que tienen una visión apoyada en el paradigma estructural funcionalista, pero habemos también muchos que tenemos una visión crítica" (Charla informal, 2018). Pareciera, como establece Castoriadis (2013), en este proceso, la institución del legein y teuhkein social, desde los acuerdos obtenidos sobre las formas del ser/hacer, decir/representar de los institucionales, han entrado en consonancia con los fundamentos ideológicos bajo los cuales se rige la UPN.

Tal vez se piense que el resultado es alentador, dado los movimientos al interior de la UPNECH, iniciados por un movimiento de maestros disidentes y alumnos de los diferentes campus en el estado, es congruente con la visión upenista originaria; quienes asumen su posición en contra de algunas manifestaciones hegemónicas por la rectoría de la universidad, al realizar de manera "tendenciosa y de manera oculta la modificación a la ley que rige la UPNECH, y derivarla al congreso el estado de Chihuahua (2017) y además, por el despido de dos directivos de dos campus de UPNECH" (2018) (charla informal). Resulta que de ese movimiento gestado y reivindicado en la actualidad, es obra de una cantidad ínfima de docentes que apoyados por su ideología, contraria a lo institucional funcionalista, ha dado frutos respecto a sus demandas (renuncia de la rectoría, el logro de nombramiento de directores provisionales a partir de la toma por parte de los estudiantes y académicos de dos Campus de UPNECH (2018), en franca oposición a la imposición por parte de la rectoría de dos directores, aunque nombrados "encargados de despacho", no deja de ser una imposición antidemocrática e 
instrumental a sus fines funcionalistas. Sin embargo, falta mucho por hacer, para instituir el legein y teuhkein de una universidad autónoma y coherente con sus principios con los que se edificaba y asumía la UPN. Por tanto, como consigna Castoriadis (2013), los muchos que no participan en el movimiento de disidencia, parecen estar sujetos a investidos en relación a una alienación institucional funcionalista, donde posiblemente no se dan cuenta de la red simbólica que los inviste y sobre todo que los sujeta y domina. Algunos agentes mencionan "para que participar, si no se logra nada, ya que lo que uno propone ni siquiera se menciona en las reuniones" y otros más "solo estoy de acuerdo que se abrogue la ley, lo de los directores, no viene al caso, por que por algo lo han de haber corrido". (Charla informal; 2018).

\section{Relaciones sociales estalladas}

La LIE al crearse en 2002, surge con el fin de formar profesionales que contribuyan a atender necesidades sociales, culturales y educativas con una capacidad de leer el contexto de manera crítica con una nueva actitud; y resolver problemas de manera ética, responsable y creativa (LIE, 2002). Freud (2007), en una revisión sociológica sobre el malestar en la cultura, establece tres condiciones que llevan al individuo a una constante fuente de tensión y desdicha; la primera encumbrada en la hiperpotencia de la naturaleza y su devastación ante su manifestación en fenómenos naturales que crean una sensación de impotencia y vulnerabilidad en el ser humano; la otra, en función del propio cuerpo, destinado al dolor y hacia la muerte inexorablemente, porque en muchos de los casos contiene genéticamente su motivo de disolución; y por último, "desde los vínculos con otros seres humanos. Al padecer que viene de esta fuente lo sentimos tal vez más doloroso que a cualquier otro" (pp. 76-77).

El autor plantea la posibilidad de atemperar tales fuentes de desdicha, a partir de tres métodos que las sofoquen: Para el primero ha realizado cierto dominio de la naturaleza a través de la ciencia y la tecnología, que en mucho ha contribuido a prevenir y contrarrestar las fuerzas de esta, pero que sin embargo aún embate y destruye al hombre y sus creaciones. La segunda, que implica protegerse de algún modo del mundo exterior, lo constituye "el método más tosco pero también el más eficaz" (p. 77), la invención de poderosas satisfacciones sustitutivas a través de sustancias químicas que embriagan y adormecen las emociones de ese malestar y desdicha, y procuran sensaciones de placer, pero que atempera de forma inmediata e ilusoria y que puede incurrir en graves peligros y daños a la vida y que además no soluciona su sentir de desdicha permanentemente. Y tercero, en 
función a las relaciones interpersonales como fuente de tensión, se visibiliza a través de un proceso psíquico complejo, a través de la sustitución de pulsiones anteriormente experimentadas como dominantes y con tendencia agresiva hacia los otros y hacia sí mismo, por su contraparte, la sublimación del impulso en descargas socialmente bien vistas y aceptadas y sin posibilidad aparente de ejercer agresión alguna hacia los otros sujetos; se observan dos formas de revelarse, una, tal es el caso del artista en el acto de crear y del científico en la solución de problemas y el conocimiento de la verdad; por desgracia esta condición solo es posible para unos cuantos en tanto se disponga de capacidades y talentos superiores, y aun así, no se garantiza la protección contra el sufrimiento; dos, la más compleja, exhibida en las relaciones vinculares directas entre los sujetos, en tanto insuficiencia de normas que regulen dichas relaciones en la familia, lo cultural y lo social, que ante su incapacidad, detonan que el otro sea visto como el "más acreedor a mi hostilidad y aun a mi odio (...), no se priva de burlarse de mí, de ultrajarme, calumniarme, exhibirme su poder" (p. 107), lo que puede desatar el impulso agresivo como respuesta. Ahora bien, los fines de la cultura al designar una serie de operaciones y normas que sirven a la fuente de protección del ser humano, respecto a la regulación de vínculos recíprocos ante los hombres, parece ser el modo en que dichos impulsos sean en cierta forma sublimados o desplazados, dado el carácter de justicia y castigo que puede hacer uso en respuesta a manifestaciones violentas en vínculos sociales, es decir, tiende a que se inhiba la disposición agresiva, y ante ello emerja una relación vincular más adecuada. Aunque en tanto desplazada o sublimada, tampoco garantiza su permanencia, dada la condición filogenética de los sujetos.

Los problemas en el grupo se deben al liderazgo de algunos integrantes, a querer imponerse sobre las ideas de los demás; que me he dado cuenta que algunas hablan mal de mí, por lo que no me siento cómodo en el grupo, todos son raros, no los soporto me caen mal, me mantengo y me siento solo en el salón, existe mucha violencia en el grupo y creo que se debe a la misma dinámica interna del grupo" (Entrevista 2018).

Se hace notar en este estudio, que existen como en todo grupo social, varios subgrupos que están conformados de 4 a 5 miembros, en donde "por lo general uno de ellos es referido como líder" (entrevista; 2018), en unos, en tanto factores académicos, de personalidad en otros y en los últimos, en base a la posición que juegan en relaciones sociales con la figura del director. Liderazgo que otorga un posicionamiento de cierta legitimidad de prestigio y de poder en el subgrupo lo que genera una rivalidad entre los 
RECIE. Revista Electrónica Científica de Investigación Educativa Vol. 4, núm. 2, enero-diciembre 2019, pp. 1083-1091.

pequeños subgrupos y con el grupo en general. Por lo tanto, en las desavenencias observadas, se pudiera dar cuenta, en primer lugar, según De Alba (1995), que existen identificaciones con estos, en tanto proceso inagotable, en la búsqueda de re-afirmaciones de identidad producto de interacciones con el otro, provocados por valoración o desvaloración del otro, dando entrada a una nueva imagen identificadora a incorporar, y como consecuencia su adhesión a esa figura que detenta poder. Lacan reafirma lo anterior, "(...)es decir se identifica y se incorpora en relación a la transformación producida en el sujeto cuando asume una imagen (...) a partir de un cuerpo fragmentado, que precisa de una imagen ortopédica que le dé una unidad" (1949; p. 100). Por consiguiente, ni la misma sublimación aceptada por la cultura, permite que en gran medida se exteriorice el impulso agresivo en las relaciones interpersonales, observando que en algunas ocasiones se intensifica. En segundo lugar, Martínez citando a Foucault (2013) establece, que el poder es un acto más que un objeto, está en todos lados, es inmanente y omnipotente, generado por las relaciones de fuerza que cobran forma entre los grupos sociales. Uno de sus métodos disciplinarios es el panóptico, permite normalizar a los individuos en masa; el individuo aprende a normalizarse-someterse no porque esté siendo observado, sino por la posibilidad que sea observado, su propósito es el control del cuerpo, al garantizar sujetar de forma constante sus fuerzas a partir de imponer una relación de utilidad, el panóptico hace aprender al individuo a auto vigilarse. "algunas de las del salón van con el director y le dicen cosas de lo que sucede en el grupo, no digo nada porque no vaya a ser que tenga consecuencias, pero realmente me da muchísimo coraje lo chismosas que son y jamás me juntaré con ellas" (Entrevista, 2018). El ojo vigilante visibilizado por el vigilado en tanto búsqueda del poder anhelado, detona que las relaciones de fuerza se expresen en conductas de oposición pero solo expresadas en malestar y agresión al interior de las relaciones sociales. Por lo tanto, ni por sublimación por identificación con el otro interiorizado, ni por la identificación con el líder institucional, en tanto otro interiorizado en tanto poder, se logran anular los mecanismos de agresión en las relaciones sociales, al contrario, estallan relaciones de fuerza de mayor intensidad. La siguiente pregunta, representa la posible elucidación de este problema: ¿Será que dado su carácter filogenético, la pulsión agresiva es incapaz de ser sublimada para mejorar los vínculos sociales; o es también, debido a la indiferencia de la cultura universitaria en la formación de sujetos, olvida que en otro tiempo, sus alumnos tenderán a solucionar conflictos educativos y las relaciones que se establecen en el ámbito 
educacional donde se desenvuelvan con una visión crítica y humanista (SEP, 2002)?

\section{Referencias}

De Alba, A. (1995), Posmodernidad y educación México, editorial. Porrúa.

Freud, S. (2007). Volumen XXI - El porvenir de una ilusión, El malestar en la cultura, y otras obras (1927-1931) (Buenos Aires/Madrid: Amorrortu, 1979).

Foucault, M. (2009). Vigilar y castigar. Nacimiento de la prisión. México: Siglo Veintiuno Editores.

De Souza Santos, B. (2007), La universidad en el siglo XXI. Para una reforma democrática y emancipatoria de la universidad. Bolivia, Ed. CIDESUMSA, ASDI y Plurar editores.

Lacan, J. (1946) "El Estadio del espejo" en Escritos I. Buenos Aires, Siglo Veintiuno Editores.

Martínez, R. (2013). Pedagogía tradicional y pedagogía crítica. Chihuahua, México. Ed. CELAPEC.

Murcia Peña, Napoleón; Gamboa Suárez, Audin Aloiso. Saber, manipulación y poder. La universidad como institución social. El ágora USB, vol. 15, núm. 1, enero-junio, 2015, pp. 115-128 Universidad de San Buenaventura Seccional Medellín Medellín, Colombia. ISSN: 16578031

Thompson, J. (1993) Ideología y cultura moderna. Teoría crítica social en la era de la comunicación de masas. México: UAM

UPN (2002), Programa de reordenamiento de la oferta educativa de las unidades UPN. 
RECIE. Revista Electrónica Científica de Investigación Educativa Vol. 4, núm. 2, enero-diciembre 2019, pp. 1083-1091. 